\title{
Self expanding stents in congenital heart disease
}

\author{
Andrew N Redington, Jochen Weil, Jane Somerville
}

\begin{abstract}
Objectives-To show potential indications for and clinical use of self expanding stents in patients with congenital heart disease.

Design-Descriptive study of selected, non-randomised patients with balloon expandable but persistent stenoses in whom the use of a balloon expandable stent was considered suboptimal or impossible.

Setting-A tertiary referral centre.

Patients-10 patients, aged 15 days to 32 years. Six patients after atriopulmonary or cavopulmonary anastomosis, two with pulmonary atresia and multiple aortopulmonary collaterals, one with coarctation of the aorta, and one with congenital pulmonary venous stenosis.

Results-Successful, uncomplicated, placement of 10 stents with the desired haemodynamic results, even in tortuous vessels with many stenoses.

Conclusions-Self expanding stents have a role in the treatment of patients with congenital heart disease. They should be considered when a smaller delivery system and flexibility would aid placement, or in the treatment of long or multiple sequential stenoses.
\end{abstract}

(Br Heart f 1994;72:378-383)

The use of intravascular stents for the treatment of peripheral vascular disease ${ }^{1}$ and coronary artery disease ${ }^{2}$ has become widespread. Their use in the treatment of congenital heart disease is also increasing. Early ${ }^{3}$ and medium term $^{4}$ results of a multicentre North American experience, by far the largest group published, have confirmed the clinical usefulness of balloon expandable stents in systemic venous and pulmonary arterial stenoses that are expandable but undilatable with standard balloon dilatation. Balloon expandable stents have also been used experimentally to stent the arterial duct as an interim palliation of the hypoplastic left heart syndrome $e^{56}$ and pulmonary atresia. ${ }^{7}$

Although the placement of those stents has generally been successful, they have some disadvantages. The larger sized stents are inserted through large bore guiding sheaths, and dislodgement from the balloon catheter with embolisation has been reported. ${ }^{4}$ Repositioning during placement is not possible and, because of their fixed tubular shape after balloon dilatation, complete apposition to the vascular wall is not always achieved. Finally, they are available in relatively short lengths and so several stents may be needed to cover a long stenosis. ${ }^{4}$

Self expanding stents have their own disadvantages but have the potential to overcome all the disadvantages of balloon expanding stents. In this study we report our preliminary experience of their use in patients with congenital heart disease.

\section{Patients and methods \\ PATIENTS}

Ten self expanding stents have been placed in 10 patients. Their age ranged from 15 days to 32 years, and they weighed 3-63 kg. The table shows their anthropometric data, diagnosis, and procedural details. Six patients had previously undergone atriopulmonary or cavopulmonary anastomoses for complex congenital heart disease. The stenosis was at an anastomosis line in five and in one with a bidirectional Glenn shunt there was a severe narrowing at the pulmonary artery end of a previous modified Blalock-Taussig shunt in the contralateral lung.

Two further patients had complex pulmonary atresia with ventricular septal defect and stents were used to dilate stenosed aortopulmonary collaterals to palliate severe resting and exercise arterial desaturation. In one 6 month old infant there was idiopathic diffuse stenosis of the pulmonary veins with severe pulmonary hypertension and syncope. Finally, a neonate with hypoplastic left heart syndrome had residual coarctation of the aorta after palliative surgery in preparation for heart transplantation. This patient was the subject of a detailed report. ${ }^{8}$

\section{METHODS}

In accord with others we have used balloon expandable stents for pulmonary artery stenosis, pulmonary vein stenosis, and systemic venous stenosis. Self expanding stents were used in these patients for the following reasons; (a) the need for a smaller shaft size $(\mathbf{n}=$ 4); (b) a complex stenosis within a tortuous
Correspondence to: Dr Andrew Redington, Sydney Street, London SW3 6NP.

Accepted for publication 2 March 1994 
Data an 10 patients treated with self expanding stents

\begin{tabular}{|c|c|c|c|c|c|c|}
\hline $\begin{array}{l}\text { Patient } \\
\text { No }\end{array}$ & $\begin{array}{l}A g e \\
(y r)\end{array}$ & $\begin{array}{l}\text { Weight } \\
(\mathrm{kg})\end{array}$ & Sex & $\begin{array}{l}\text { Underlying diagnosis or } \\
\text { relevant operations }\end{array}$ & $\begin{array}{l}\text { Stent size } \\
(\mathrm{mm})\end{array}$ & Outcome \\
\hline 1 & 5 & 22 & $\mathrm{~F}$ & $\begin{array}{l}\text { PA with IVS, previous left B-T shunt, } \\
\text { right bidirectional Glenn stunt: left } \\
\text { pulmonary artery stenosis }\end{array}$ & $7 \times 35$ & $\begin{array}{l}\text { Complete relief of stenosis } \\
\text { (fig 1) }\end{array}$ \\
\hline 2 & 6 & 23 & $M$ & $\begin{array}{l}\text { Absent left connexion, TGA: total } \\
\text { cavopulmonary anastomosis; } \\
\text { IVC/baffle stenosis }\end{array}$ & $20 \times 80$ & $\begin{array}{l}\text { Relief of stenosis: resolution of } \\
\text { ascites. }\end{array}$ \\
\hline 3 & 9 & 46 & $\mathbf{F}$ & $\begin{array}{l}\text { DILV, TGA: right classical Glenn } \\
\text { procedure: IVC to left pulmonary } \\
\text { artery connection (14 mm Goretex) } \\
\text { stenosed }\end{array}$ & $14 \times 33$ & $\begin{array}{l}\text { Complete relief of stenosis } \\
\text { (fig 2) }\end{array}$ \\
\hline 4 & 10 & 44 & $\mathrm{~F}$ & $\begin{array}{l}\text { Tricuspid atresia, TGA, direct } \\
\text { atriopulmonary anastomosis: left } \\
\text { pulmonary artery stenosis at insertion } \\
\text { of narrowed homograft }\end{array}$ & $16 \times 33$ & Complete relief of stenosis \\
\hline 5 & 17 & 48 & $\mathbf{F}$ & $\begin{array}{l}\text { Absent right connexion, TGA: direct } \\
\text { atriopulmonary anastomosis, long } \\
\text { right pulmonary artery stenosis }\end{array}$ & $14 \times 33$ & $\begin{array}{l}\text { Mean gradient abolished: } \\
2 \mathrm{~mm} \mathrm{Hg} \mathrm{"a} \mathrm{wave"} \mathrm{gradient}\end{array}$ \\
\hline 6 & 26 & 53 & $\mathbf{M}$ & $\begin{array}{l}\text { Classical tricuspid atresia: stenosed } \\
\text { homograft between RA and pulmonary } \\
\text { artery }\end{array}$ & $16 \times 42$ & $\begin{array}{l}\text { Mean gradient abolished: } \\
1 \mathrm{~mm} \mathrm{Hg} \text { "a wave" gradient }\end{array}$ \\
\hline 7 & 0.04 & $3 \cdot 2$ & $\mathbf{M}$ & $\begin{array}{l}\text { HLHS: previous aortopulmonary } \\
\text { anastomosis, baffled pulmonary } \\
\text { arteries: severe residual coarctation. }\end{array}$ & $8 \times 15$ & Complete relief of coarctation \\
\hline 8 & 0.5 & $5 \cdot 1$ & $\mathbf{M}$ & $\begin{array}{l}\text { Diffuse, diopathic pulmonary vein } \\
\text { stenosis: stent in left pulmonary vein. }\end{array}$ & $6 \times 20$ & $\begin{array}{l}\text { Excellent relief but later } \\
\text { restenosis (see text) }\end{array}$ \\
\hline 9 & 24 & 56 & $\mathbf{M}$ & $\begin{array}{l}\text { Pulmonary atresia, VSD, MAPCAs: } \\
\text { stenosed collateral to right lung }\end{array}$ & $8 \times 48$ & $\begin{array}{l}\text { Resting arterial saturation } 67 \% \text { - } \\
83 \% \text { (fig 3) }\end{array}$ \\
\hline 10 & 32 & 63 & $\mathbf{F}$ & $\begin{array}{l}\text { Pulmonary atresia, VSD, MAPCAs: } \\
\text { stenosed collateral to right lung. }\end{array}$ & $8 \times 32$ & $\begin{array}{l}\text { Resting arterial saturation } 66 \%- \\
86 \%\end{array}$ \\
\hline
\end{tabular}

PA, pulmonary atresia; IVS, intact ventricular septum; B-T, Blalock Taussig Shunt; TGA, transposition of great arteries; IVC, inferior vena cava; DILV, double inlet left ventricle; HLHS, hypoplastic left heart syndrome; MAPCAs, multiple aortopulmonary inferior vena
collaterals.

or curved vessel $(n=5)$; $(c)$ long or multiple stenoses $(n=3)$; (d) difficult or unstable access with a standard long sheath or wire making placement of a balloon expandable stent hazardous $(\mathbf{n}=3)$; or $(e)$ the need for a stent size larger than $18 \mathrm{~mm}(\mathrm{n}=1)$, or $(f)$ a combination of these. Cardiac catheterisation was performed under general anaesthesia. Standard balloon dilatation catheters and techniques were used. High pressure balloons were not used, as in all of these patients the stenosis was dilated with low pressure balloons, but restenosis occurred during deflation. In one patient (patient 1) dissection of the pulmonary artery was evident on angiography after balloon dilatation, with almost total occlusion at the site of a complex stenotic lesion at the insertion of a previous Blalock-Taussig shunt.

A $20 \mathrm{~mm}$ self expanding $Z$ stent (Gianturco-Cooks instruments) was used in patient 2. This stent was chosen because of its large size. In the rest, a self expanding wall stent (Medinvent-Schneider) was used. The details of their construction and placement have been published elsewhere. ${ }^{9}$ Briefly, these stents are mounted on relatively small catheters (overall diameter 5-9 French (F)) and are held behind a rolling membrane. They are positioned directly over a wire without the need for a long sheath across the stenosis, and have the advantages of small shaft size with some flexibility of the device before release. The device is placed by withdrawing the rolling membrane across the stent, which therefore expands from its more distal to its proximal end. A variable degree of shortening occurs during expansion depending on ultimate diameter. But this system has the potential advantage of allowing placement of the distal part of the stent distal to the stenosis, and then subsequently withdrawing the device up to the stenosis to ensure exact positioning of the device across the stenosis. This technique was used in five of the patients.

The lengths of the stents ranged from 1.5 to $4.8 \mathrm{~cm}$ with the diameter chosen so that apposition to the vessel proximal and distal to the stenosis was assured $(8-16 \mathrm{~mm})$. These stents "model" to the vessel shape and diameter and so the maximal diameter, either proximal or distal, was taken. When there was a considerable difference between the proximal and distal diameters less shortening of the device was expected and the appropriate length was chosen accordingly.

In two patients there was incomplete expansion of the device, which had an hourglass appearance after placement. Satisfactory expansion was achieved in both by a second balloon dilatation of the stenosis from within the stent, with the same balloon used for the initial dilatation.

Procedural systemic heparinisation with 50 $\mathrm{IU} / \mathrm{kg}$ of heparin was used in all patients. This was continued by infusion (400 $\mathrm{IU} / \mathrm{kg} /$ day) that lasted for 48-72 hours after the procedure, during which time systemic anticoagulation with warfarin was established. 


\section{Results}

The table shows the size and length of each stent. There were no procedural complications related to stent placement and the final position of the stent was thought to be optimal in all patients.

\section{ATRIOPULMONARY AND CAVOPULMONARY ANASTOMOSIS}

Six stents were used in six patients. In one patient (patient 2, table) a $20 \mathrm{~mm} \mathrm{Z}$ stent was placed across a stenosed anastomotic line between the inferior caval vein and the intraatrial baffle three weeks after the operation. There was complete relief of the pressure gradient and resolution of persistent ascites, but the patient remained severely compromised. His late postoperative course was complicated by recurrent periods of low cardiac output and pleural effusions. Repeat cardiac catheterisation confirmed complete relief of the stenosis of the inferior vena cava by the stent. $\mathrm{He}$ died three months later with multisystem failure.

Wall stents were used in all other patients. The diameter used was $7 \mathrm{~mm}$ in patient 1 , in whom there was a severe $(<2 \mathrm{~mm})$ pulmonary arterial stenosis at the site of a previous Blalock-Taussig shunt on the contralateral side to a bidirectional Glenn anastomosis. Balloon dilatation $(6 \mathrm{~mm})$ through the right internal jugular vein led to a dissection of the pulmonary artery with almost complete occlusion (fig 1). It was impossible to pass a long $8 \mathrm{~F}$ guiding sheath through the tortuous and dissected area, but the $7 \mathrm{~F}$ wall stent delivery system passed

Figure 1. Digital subtraction angiograms from patient 1 (see table) after balloon dilatation of $a$ severe proximal left pulmonary artery stenosis. (A) An injection through the bidirectional Glenn anastomosis. The

pulmonary artery has dissected and there is virtually no flow to the left lung. $(B)$ the area distal to the dissected stenotic segment, there is also a discrete stenosis of the left lower lobe artery; (C) the position of the self expanding stent that has been placed to traverse the two narrowed areas; (D) Angiogram after operation that shows both relief of stenoses and filling of the upper lobe branches through the stent.
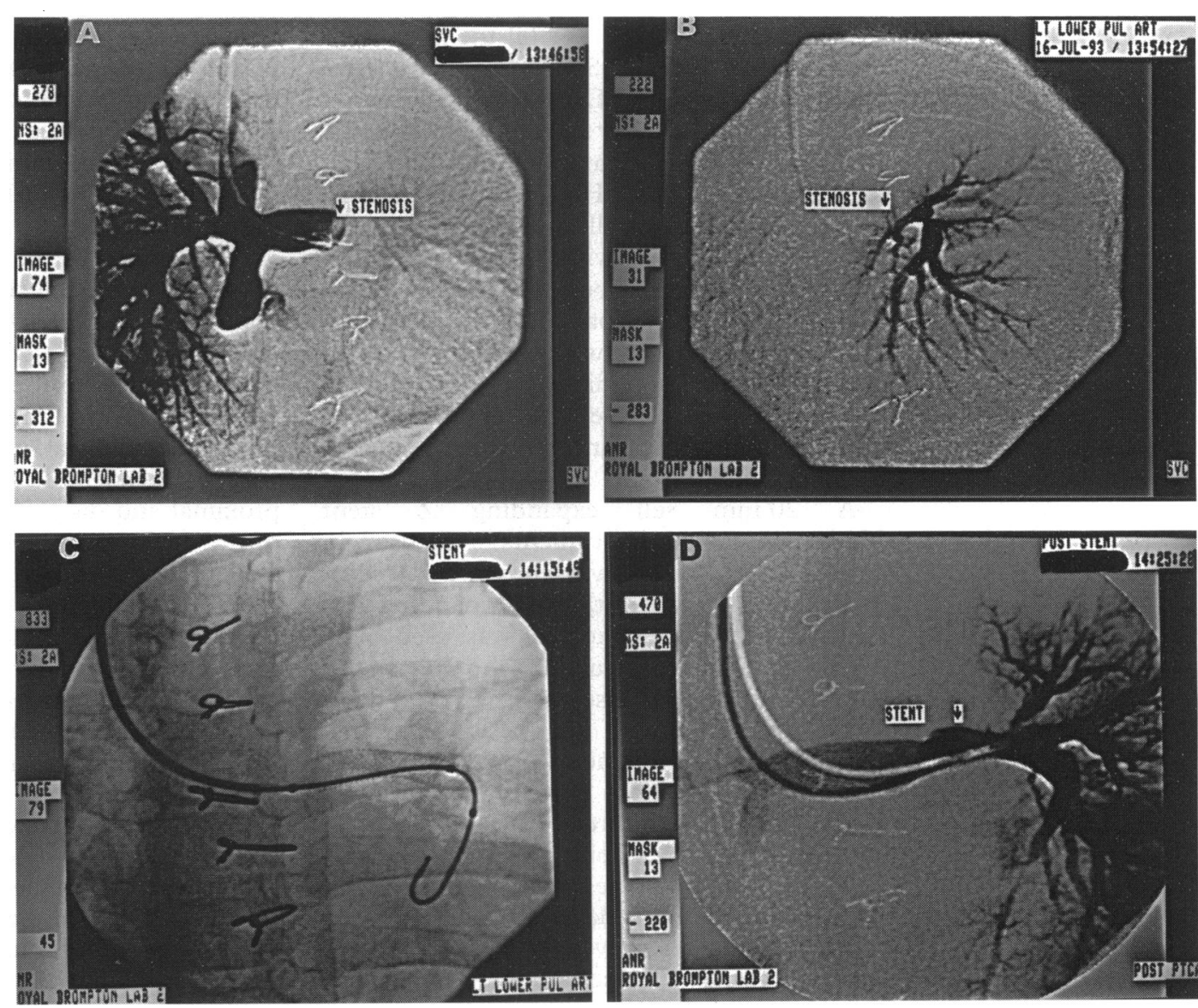

without difficulty. There was complete relief of the stenosis (fig 1) and restoration of blood flow to the left lung. A $14 \mathrm{~mm}$ stent (length $33 \mathrm{~mm}$ ) was used in two patients. In one there was stenosis at the anastomosis line between a $14 \mathrm{~mm}$ intra-atrial conduit and the left pulmonary artery. Figure 2 is from this patient and illustrates the capacity for these stents to mould to the shape of the vessel, yet maintain a smooth, uniform diameter. In the other patient (patient 5) there was a long stenosis from the origin of the right pulmonary artery, after a direct atriopulmonary anastomosis. A $16 \mathrm{~mm}$ stent was used in the other two patients. Both had long stenoses originating at the site of a previous homograft connection between the right atrium and pulmonary artery. The mean pressure gradient across the stenosis was median (range) 5 (1-10) $\mathrm{mm} \mathrm{Hg}$. This was completely abolished in all patients $(p<0.001)$. The "a wave" gradient measured in three patients was 6,8 , and $10 \mathrm{~mm} \mathrm{Hg}$, and fell to 0,1 , and $2 \mathrm{~mm} \mathrm{Hg}$ respectively.

There were four other patients in whom self expanding stents were used (table). Patient 7 has been described in detail elsewhere. ${ }^{8}$ One infant (patient 8) presented with tachypnoea, syncope, and signs of pulmonary hypertension. The echocardiographic diagnosis of idiopathic diffuse pulmonary vein stenosis was confirmed at cardiac catheterisation. A common left middle and lower lobe pulmonary vein was most severely affected, but after transvenous balloon dilatation (through a patent foramen ovale) the mean gradient between pulmonary vein and left 
Figure 2 (A) Anteroposterior and $(B)$ lateral angiograms of the inferior caval to pulmonary artery connection in patient 2.

There is a severe stenosis at the anastomotic line despite balloon dilatation. (C)

Anterioposterior and (D)

lateral angiograms

immediately after release of the stent from the delivery

system. Note how the

device takes the shape of

the vessel, maintaining its smooth curvature. $(E)$

Anteroposterior and $(F)$

lateral angiograms after

stent placement. There is

complete relief of the

stenosis.
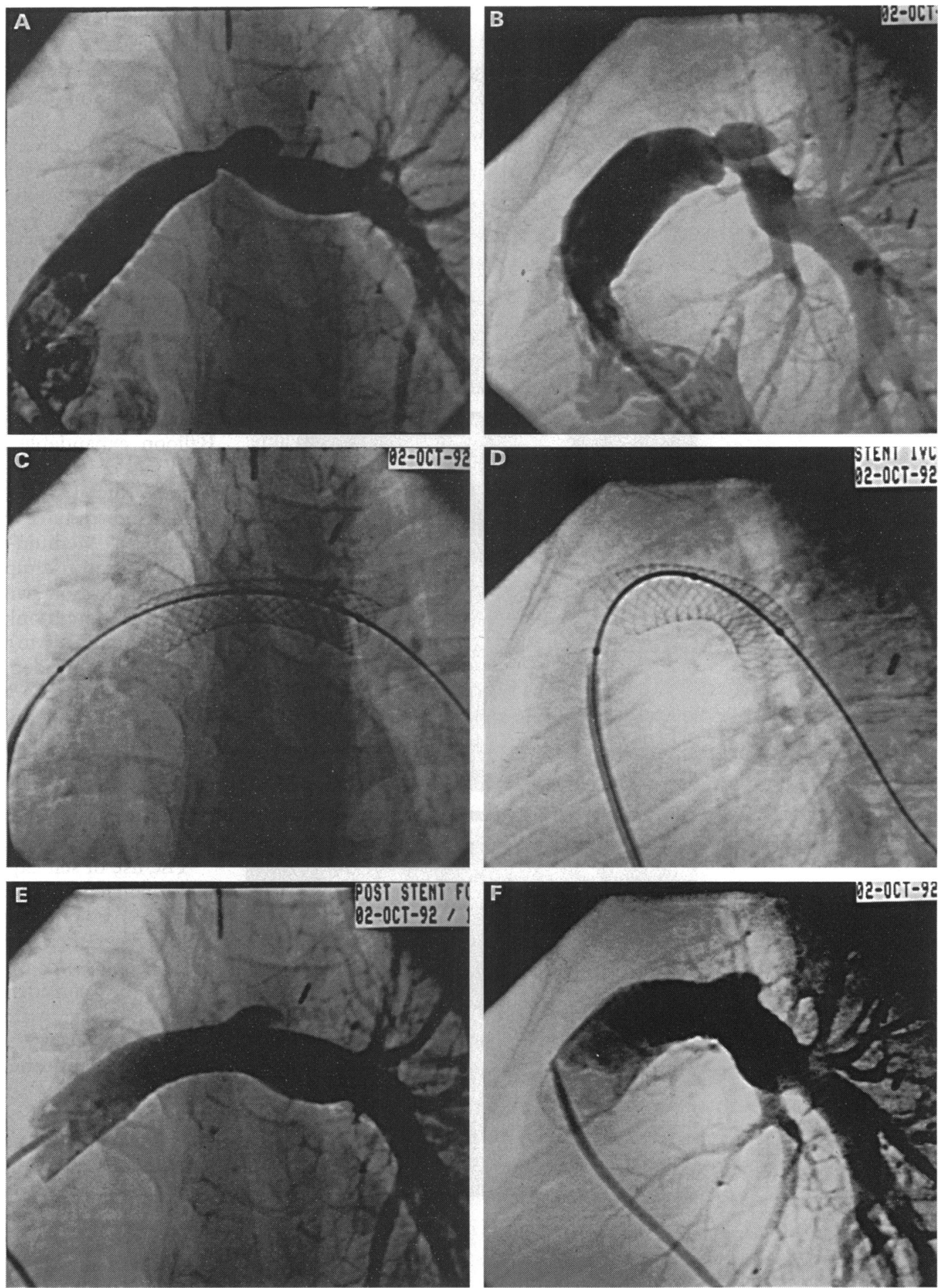

atrium fell from $24 \mathrm{~mm} \mathrm{Hg}$ to $13 \mathrm{~mm} \mathrm{Hg}$. A $6 \mathrm{~mm}$ wall stent was placed across the stenosis, further reducing the mean gradient to $3 \mathrm{~mm} \mathrm{Hg}$. The right ventricular pressure fell from 1.3 times the systemic pressure to about 0.5 times. There was symptomatic improvement and no further syncopal episodes for six weeks. At presentation after a further syncopal episode cardiac catheterisation showed restenosis within the lumen of the stent (mean gradient $20 \mathrm{~mm} \mathrm{Hg}$ ) and progression of stenosis of the right sided pulmonary veins. Intraoperative stenting with balloon expandable stents in four veins was initially successful, the right ventricular pressure again falling from suprasystemic to less than half systemic levels. This patient died during a presumed pulmonary hypertensive crisis while self ventilating 48 hours after the operation.

Finally, two severely cyanosed patients with pulmonary atresia, ventricular septal defect, and multiple aortopulmonary collaterals had stents inserted into a stenotic collateral artery that supplied most of the pulmonary vasculature of the right lung. Neither patient had central pulmonary arteries and both had pulmonary vascular disease in most or all of the left lung. In patient 10 the collateral had two sequential stenoses needing an $8 \times 32 \mathrm{~mm}$ long stent. In patient 9 
Figure 3 (A) Digitally subtracted angiogram of the long stenosed aortopulmonary collateral supplying the right lung in patient 9; (B) magnified image after stent

placement. Note how the single $8 \times 48 \mathrm{~mm}$ stent traverses the full length of the stenosed vessel. (C) Angiogram after the procedure. Arterial oxygen saturation rose from $67 \%$ to $83 \%$
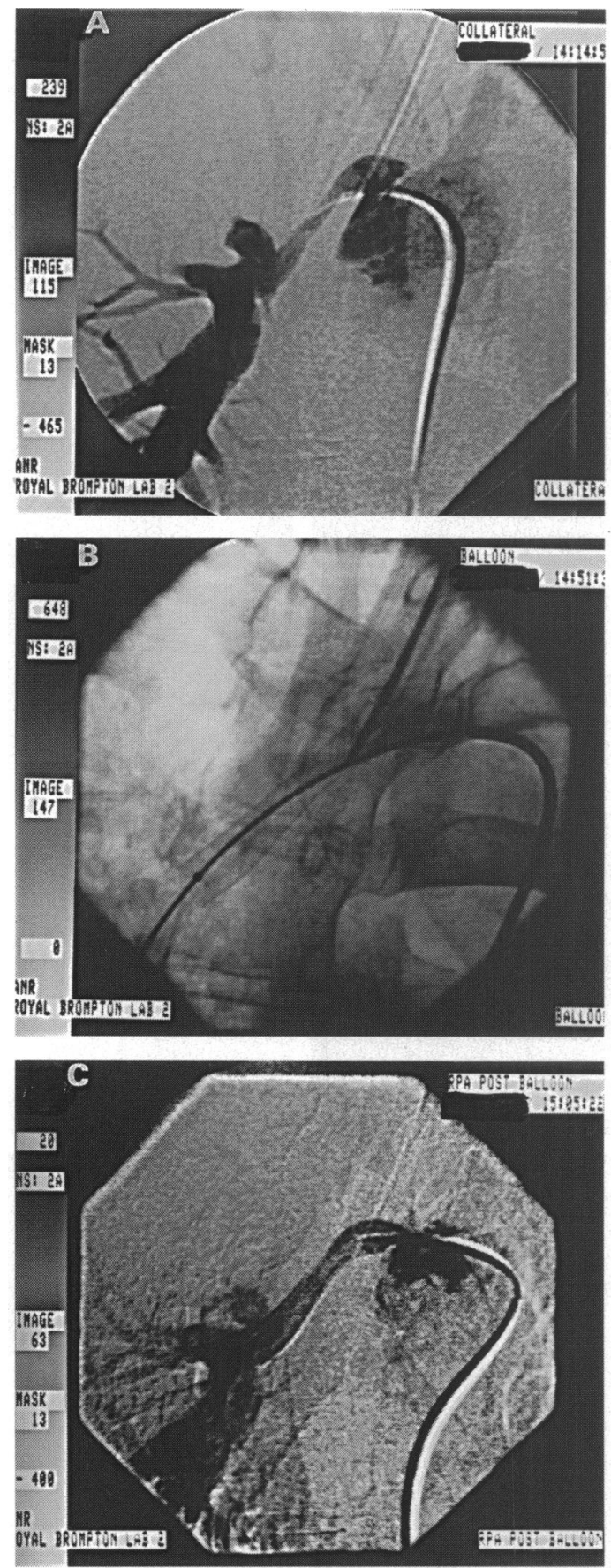

the collateral arose from the junction of the ascending aorta with the brachiocephalic artery and was diffusely stenosed over its $4.5 \mathrm{~cm}$ length. A single $8 \times 48 \mathrm{~mm}$ stent was placed between the ampulla of the collateral and distal pulmonary artery (fig 3 ). The resting preoperative arterial oxygen saturation of the two patients was $66 \%$ and $67 \%$ rising to $86 \%$ an $83 \%$, after the procedure. Both patients reported improved symptoms and exercise tolerance.

FOLLOW UP

The three youngest patients in this series have subsequently died, all had notable physiological and symptomatic improvement immediately after insertion of the stent and died due to events unrelated to the original stenting procedure. Post mortem examinations were performed in two. The results in patient 7 were described previously. ${ }^{8}$ In patient 8 , the lumen of the original wall stent was narrowed by fibrointimal hyperplasia, accounting for the restenosis. This had been partially relieved by the direct placement of a balloon expandable stent at its junction with the left atrium. Follow up in the other patients ranges from three to 15 months. There have been no adverse events. Three patients have undergone repeat cardiac catheterisation (two, three, and eight months later) for other reasons. No change in anatomy or pressure gradient across the stent was shown.

\section{Discussion}

Balloon expandable stents have successfully been used to relieve pulmonary arterial, venous, ductal, and conduit stenoses in children and adults with congenital heart disease. ${ }^{3610}$ Medium-term follow up confirms the long-term usefulness of these devices and their application will become more widespread. Although only rarely important, there are disadvantages to their use. Large delivery sheaths are needed and malposition and embolisation due to displacement of the stent from the balloon catheter has been described. ${ }^{47}$ Furthermore, intention to treat data are not available. For example, it is unclear how often a stent procedure is abandoned because of difficulty in traversing a tortuous stenosis.

The use of self expanding stents in patients with congenital heart disease has been described in previous case reports. ${ }^{81112}$ Our small experience shows the advantages of these stents and we believe that their use should be considered in certain circumstances. Their main advantages are their smaller delivery system and their flexibility both before and after placement. Thus even tortuous complex stenoses, such as those encountered in the aortopulmonary collaterals in two of our patients can be traversed with this over the wire system. After placement this flexibility allows for modelling of the stent to the vessel wall maintaining a smooth internal diameter to the vessel, the orientation of which is unaltered by placement of the stent (fig 2). The size of the delivery system is generally smaller than that of the balloon expandable equivalent. Transarterial placement of an $8 \mathrm{~mm}$ stent to relieve postoperative coarctation in patient 7 was made possible by the $5 \mathrm{~F}$ delivery system and in patient 1 it was not possible to traverse the tortuous and dissected pulmonary artery at the site of a dilated stenosis with a standard $8 \mathrm{~F}$ delivery sheath. The $7 \mathrm{~F} 7 \mathrm{~mm}$ self expanding stent delivery system tracked over a standard guidewire without difficulty (fig 1). While completely relieving the near total occlusion of this vessel, this case shows one of the disadvantages of this type of stent. Unlike balloon expandable stents, self expanding stents cannot be overdilated beyond their preset limits. Balloon expandable stents have the theoretical possibility of sequential dilatation 
to keep pace with somatic growth, and preliminary data suggests that this may sometimes be successful. ${ }^{13}$

This is not a problem when a fixed dilatation is needed, such as was the situation in our two adult patients with aortopulmonary collaterals. Not only was transarterial access to these stenotic and tortuous vessels, (which arose from the ascending and descending aorta) made straightforward by the inherent flexibility of the mounted and positioned stent, but the ability to stent multiple or long diffusely stenosed vessels with a single device was also made possible. In our cases 32 and $48 \mathrm{~mm}$ long stents were used, but lengths of up to $110 \mathrm{~mm}$ are available. This avoids the need for multiple and perhaps prolonged stenting procedures with overlapping stents. This should provide cost benefits and ease of the procedure, and may possibly improve flow characteristics through the stent. Even so, we have elected to anticoagulate all of our patients in the absence of data to the contrary. The length of the stent will of course, vary depending on the ultimate diameter of the stent. Considerable shortening occurs when fully expanded, but allowances must be made if incomplete or variable expansion is anticipated. The manufacturers now provide a guide to placed length $v$ vessel diameter, but for variable vessels stent selection remains somewhat subjective.

Finally, although it is not known exactly and varies with stent size and length, the radial force applied by the self expanding stent is about equivalent to a balloon dilatation pressure of 5-6 atmospheres (personal communication, Schneider UK). We therefore restricted the use of these stents to easily dilatable but elastic stenoses. Despite this a repeat balloon dilatation was needed immediately after placement of the stent because of residual stenosis in two patients. Complete relief was obtained, but it is our practice only to use these stents after standard low pressure balloon dilatation. Resistant stenoses, or those that need higher pressure balloon $(>6$ atmospheres) dilatation, should be treated by insertion of balloon dilatable stents that are far more rigid after expansion.

In summary, self expanding stents have some advantages over balloon expandable stents and should be considered when a smaller delivery system and flexibility would aid placement, or where the treatment is of long or multiple sequential stenoses.

We thank our cardiological and surgical colleagues at the Royal Brompton Hospital for their support and Dr B Keaton (Southampton) for referring patient 3.

1 Palmaz JC, Laborde JC, Rivera FJ, Encarnacion CE, Lutz JD, Moss JG. Stenting of the iliac arteries with the JD, Moss JG. Stenting of the iliac arteries with the Palmaz stent: experience from a multice

2 Goy JJ, Sigwart U, Vogt P, Stauffer JC, Kaufmann U, Urban P, Kappenberger L. Long-term follow-up of the first 56 patients treated with intracoronary self-expanding stents (the Lausanne experience). Am $\mathcal{f}$ Cardiol 1991;67:569-72

3 O'Laughlin MP, Perry SB, Lock JE, Mullins CE. Use of endovascular stents in congenital heart disease. Circulation 1991;83:1923-39.

4 O'Laughlin MP, Slack MC, Grifka RG, Perry SB, Locke E, Mullins CE. Implantation and intermediate-term follow-up of stents in congenital heart disease. Circulation 1993;88:605-14.

5 Ruiz CE, Gamra H, Zhang HP, Garcia EJ, Boucek MM. Stenting of the ductus arteries as a bridge to cardiac transplantation in infants with the hypoplastic left heart syndrome. N Engl $\mathcal{Y}$ Med 1993;328:1605-8.

6 Gibbs J, Wren C, Watterson KG, Hunter S, Hamilton IRs JL, Wren C, Watterson KG, Hunter S, Hamilto RL. Stenting of the arterial duct combined with banding of the pulmonary arteries and atrial septectomy or septostomy: a new approach to palliation for the
hypoplastic left heart syndrome. Br Heart $\mathcal{f} 1993 ; 69$ : h51-6.

7 Gibbs JL, Rothman MT, Rees MR, Parson JM, Blackburn ME, Rviz CE. Stenting of the arterial duct: a new approach to palliation for pulmonary atresia. $B$ Heart fै 1992;67:240-6.

8 Redington AN, Hayes AM, Ho SY. Transcatheter sten implantation to treat aortic coarctation in infancy. $\mathrm{Br}$ Heart f 1993;69:80-3.

9 Sigwart U, Puel J, Mirkovitch U, Joffre F, Kappenberger L. Intravascular stents to prevent occlusion and restenosis after transluminal angioplasty. $N$ Engl f Med 1987 316:701-6.

10 Hoskin MC, Benson LN, Nakanishi T, Burrows PE Williams WG, Freedom RM. Intravascular stent proshesis for right ventricular outflow obstruction. $\mathscr{f} A m$ Coll Cardiol 1992;20:373-80.

11 Chatelain P, Meier B, Friedli B. Stenting of superior vena cava and inferior vena cava for symptomatic narrowing after repeated atrial surgery for d-transposition of the after repeated atrial surgery for d-transpo

12 Mulcahy D, Sigwart U, Somerville J. Successful stenting of a life threatening pulmonary arterial stenosis. $B r$ of a life threatening

13 Ing FF, Grifka RG, Nihill MR, Mullins CE. Redilation of intravascular stents in congenital heart defects. Circulation 1993;88 (suppl 4):I-389. 